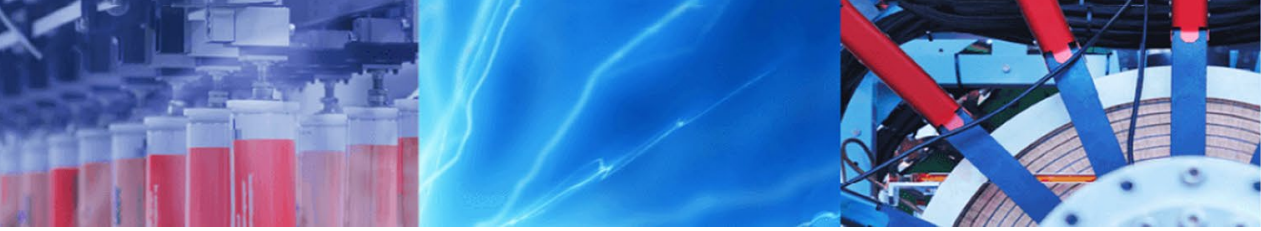

Research Article

\title{
Study of magneto-hydrodynamics (MHD) impacts on an axisymmetric Casson nanofluid flow and heat transfer over unsteady radially stretching sheet
}

\author{
Faraz Faraz $^{1}$. Sajjad Haider ${ }^{3}$ Syed Muhammad Imran ${ }^{2}$
}

Received: 19 August 2019 / Accepted: 25 November 2019 / Published online: 3 December 2019

(c) Springer Nature Switzerland AG 2019

\begin{abstract}
The current study is presented to probe the impacts of thermal radiation and mixed convection of axisymmetric Casson fluid flow in the presence of magnetic field along with nano-particles. The flow is provoked because of unsteady radially stretching sheet. The solution of transformed ordinary differential equations is attained by utilizing Keller-box finite difference method (IFDM). The influence of different parameters on flow features is sketched through various graphs and results are tabulated and argued briefly. The convection conditions on the wall temperature and concentration are also exerted in the study. Finally, a comparison is established with existing literature to support our results and a good agreement is found which corroborates our work. A decline in both velocity and temperature is witnessed with the rise in Casson parameter. It is also observed that with the rise Brownian motion and Thermophoresis parameters, the temperature of the fluid rises but concentration profile decreases in start and then start increasing. The fluid concentration in its boundary layer decreases with the increase of heavier species, the parameter of the reaction rate and the exponent of power law for fluid having Prandtl number $=10.0,15.0$, and 20.0. Moreover, the fluid velocity depreciates with the rise in unsteadiness parameter while a significant decrease in temperature is noted. The outcomes of study are quite useful in fabrication of magnetic nano-materials and high temperature treatment of magnetic nano-polymers.
\end{abstract}

Keywords Casson nano-fluid · Heat transfer - Unsteady flow · Stretching sheet · Keller-box-implicit-finite-difference method

\section{Introduction}

The study of non-Newtonian fluids flow and their characteristics is of great importance for authors due to their remarkable applications in industrial products and procedures. These fluids have non-linear relation between stress and rate of strain while Newtonian fluid model has a linear relations mode. Examination of flow field and its characteristics in these fluids is quite difficult as compared to Newtonian fluids. In general, flow of such fluids is not possible to explain by single constitutive equation. Hence, different governing equations are presented to handle the diversity of such fluids. Metzner and Otto [1], presented a brief description about the shear rate of a non-Newtonian fluid and importance of its rheological behavior. He also examined the relationship between impeller speed and the shear rate of the fluid. Parand [2], explored a numerical computational technique to find out the behavior of non-Newtonian boundary layer flow.

Sajjad Haider, Sajjadsaleem266@hotmail.com; Faraz Faraz, Faraz2019cn@outlook.com; Syed Muhammad Imran, syedsiim@gmail.com | ${ }^{1}$ Department of Applied Mathematics, Northwestern Polytechnical University, Xi'an 710000, People's Republic of China. ${ }^{2}$ College of Applied Science, Beijing University of Technology, Beijing 100124, People's Republic of China. ${ }^{3}$ Department of Mathematics, Government Postgraduate Gordon College, Rawalpindi 46000, Pakistan. 
Casson fluid model is one of the most popular nonNewtonian fluid model in order to express flow curves for blood. It is most realistic fluid model due to its practical implications in bio medical field and polymer processing. For practical purposes, it provides a convenient means for evaluating the two characteristics; Cason viscosity and the apparent yield stress. Casson [3], initially presented this model to describe the flow curves of suspensions of pigments in the preparation of printing inks. Later, Scott Blair [4], discovered that the model could describe flow curves of blood. The idea was further verified by $[5,6]$, and the model has received much attention of researchers in order to elaborate blood flow curves. Makinde et al. [7], explored the impacts of Lorentz force and heat transmission of MHD Casson fluid flow over a thermally stratified melting horizontal surface. Gireesha et al. [8] studied Cason Nanofluid with buoyancy forces and thermal radiation over stretching sheet. They utilized shooting technique along with Runge-Kutta method to achieve the numerical solution. Hari Krishna et al. [9] presented impacts of chemical reaction on Casson fluid flow with permeable stretching sheet. Makinde et al. [10] examined Cattaneo-Christov heat flux on Casson nanofluid flow past a stretching cylinder. Ibrahim and Makinde [11] explored MHD flow of Casson nanofluid on stretchable surface convective boundary and slip effects in the neighborhood of stagnation point. In past few decades, vast amount of literature is produced on the subject of heat transmission in the Casson fluid flow and numerous cases of fluid flows have been discussed including boundary layer flows [12-16].

Recent advancements in heat transfer phenomena have led to the development of nano fluids which are homogenous mixtures of base fluids suspended with metallic or non-metallic elements of diameter less than $100 \mathrm{~nm}$. Usually, the base fluids such as engine oils, water, organic liquids, ethylene glycol mixtures, etc. exhibit low thermal conductivity. A suspension of small particles/fiber as nanometer sized in a base fluid can be enhanced in carrier of liquid properties (thermal conductivity, viscosity, density, mass diffusivity) and is regarded as nanofluid the metallic nanoparticles commonly used for nano-fluids are copper $(\mathrm{Cu})$, silver $(\mathrm{Ag})$, gold $(\mathrm{Au})$ whereas the nonmetallic nanoparticles are oxides such as aluminum oxide $\left(\mathrm{Al}_{2} \mathrm{O}_{3}\right)$, copper oxide (Cuo), zinc oxide (Zno), titanium dioxide $\left(\mathrm{TiO}_{2}\right)$ and numerous forms of carbons. The terminology of nano-fluids was initially introduced by [17]. The significance of these fluids is observed due to their high heat transmission and cooling ability with very low gravitational settling in fluid flows. In recent decades, vast amount of literature is generated on the subject of heat transmission in nano-fluids and numerous cases of fluid flows have been discussed including boundary layer flows [18-22].
Mixed convection phenomena occur when forced and natural convection mechanisms act together to transfer heat. In past decade many authors have reported on convective heat transmission over stretching/shrinking surfaces due to their applications in engineering including thermal insulation, solar collector and atmospheric boundary-layer flows. The pioneer study on mixed-convection fluid flow was reported by [23], they explored heat transformation effects about non-isothermal body subjected to a non-uniform free stream velocity [24], and examined the behavior of free-convection magneto-hydro-dynamics boundary layer flow of an incompressible electrically conducting fluid in a porous media. Comprehensive studies are reported to investigate the mixed convection flow and heat transmission over unsteady radially stretching/shrinking sheet $[25,26]$.

Extension in the boundary-layer theory is a quite challenging task. This difficulty is caused by the diversity of non-Newtonian fluids in their constitutive behavior and their elastic and viscous properties. B.C. Sakidis gave the idea of axisymmetric flow and examined the behavior of solid surfaces on boundary layer flow [27]. After this theoretical investigation, various aspects of stretching surfaces which involve flow and heat transmission phenomena were explored by different researchers and a considerable quantity of literature is produced [28-33]. The studies reported above considered the steady flow. However, unsteadiness becomes an essential component of study in various engineering procedures in the case when flow depends upon time. Unsteady flow over impulsively stretched sheet at time $t=0$ with varying velocity was investigated by [34]. A good amount of literature is produced on unsteady flows to investigate the heat transmission phenomena in the studies [35-38]. Presented unsteady axisymmetric flow of nano-fluid over a radially contracting sheet in the presence of magnetic field and partial slip [39]. Proposed the series solution of unsteady axisymmetric flow and heat transfer over a radially stretching sheet [40]. The case of time-dependent

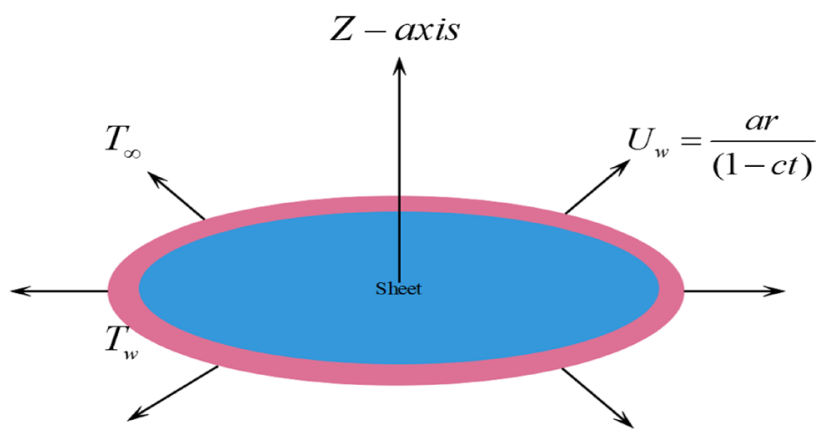

Fig. 1 Physical model and coordinate system 
radially contracting surface with heat transmission was discussed by [41]. Examined the non-similar solution of third grade fluid flow with radially stretching sheet [42]. Studied the MHD flow behavior and heat transmission past a permeable stretching sheet with slip conditions [43]. Moreover, Explored homogeneous/heterogeneous reactions and melting heat transmission impacts in the MHD flow by a contracting sheet with variable thickness [44]. MHD stagnation point flow of Jeffrey fluid by a radially stretching surface with viscous dissipation and Joule heating was investigated by [45].

The purpose of present study is to explore MHD Axisymmetric Casson nanofluid free convection flow and heat transfer over unsteady radially stretching sheet attend very less attention. To the best of our knowledge, the proposed scheme of work have not yet been discussed and the results obtained here are new. The suitable transmutations are utilized to transform partial differential equations into ordinary differential equations which are solved via Keller-box finite difference method. A decline in velocity and temperature is observed with a rise in Casson parameter. Moreover, the fluid velocity initially decreases with the rise in unsteadiness parameter while temperature decreases significantly (Fig. 1).

$\Psi(\mathrm{r}, \mathrm{z})=-r^{2} U_{w} \operatorname{Re}^{-\frac{1}{2}} f(\eta), \quad \eta=\frac{z}{r} \operatorname{Re}^{\frac{1}{2}}, \quad \theta(\eta)=\frac{T-T_{\infty}}{T_{w}-T_{\infty}}$

\section{Mathematical formulation}

Consider a two-dimensional laminar incompressible magneto-hydrodynamic unsteady flow of an electrically-conducting Cason nanofluid from a radially stretching sheet. The flow occurs because of the unsteady stretching of the surface in the radial direction with velocity $U_{w}=\frac{a r}{1-c t}$ is the stretching velocity $r$ and $z$ are components of velocity. We suppose temperature of the form $T_{w}=T_{\infty}+\frac{b r}{1-c t}$ is the wall temperature, $T_{\infty}$ is the ambient fluid temperature with $T_{w}>T_{\infty}$ where $\mathrm{a}, \mathrm{b}$ and $\mathrm{c}$ are constant. Here $a>0, b \geq 0$ and $c \geq 0$ are constants having dimension $1 /$ times $(t)$, where $t$ stands for time such that the product $c t<1$. In this analysis the velocity and the temperature field is taken $v=[(u(r, z, t), 0, w(r, z, t))], T=T(r, z, t)$.

The governing equations of flow are as under $[41,46]$,

$\frac{\partial u}{\partial r}+\frac{u}{r}+\frac{\partial w}{\partial z}=0$

$\frac{\partial u}{\partial t}+u \frac{\partial u}{\partial r}+w \frac{\partial u}{\partial z}=v\left(1+\frac{1}{\beta}\right)\left(\frac{\partial^{2} u}{\partial z^{2}}\right)-\frac{\sigma B^{2}}{\rho} u+g \beta_{T}\left(T-T_{\infty}\right)$

$$
\begin{aligned}
& \frac{\partial T}{\partial t}+u \frac{\partial T}{\partial r}+w \frac{\partial T}{\partial z}=\frac{k}{\left(\rho c_{p}\right)_{f}} \frac{\partial^{2} T}{\partial z^{2}}+\tau\left\{D_{B}\left(\frac{\partial C}{\partial r} \cdot \frac{\partial T}{\partial z}\right)+\frac{D_{T}}{T_{\infty}}\left(\frac{\partial T}{\partial z}\right)^{2}\right\} \\
& +\frac{\mu}{\left(\rho c_{p}\right)_{f}}\left(1+\frac{1}{\beta}\right)\left(\frac{\partial u}{\partial z}\right)^{2}+\frac{\sigma B^{2}}{\left(\rho c_{p}\right)_{f}} u^{2} \\
& \frac{\partial C}{\partial t}+u \frac{\partial C}{\partial r}+w \frac{\partial C}{\partial z}=D_{B} \frac{\partial^{2} C}{\partial z^{2}}+\frac{D_{T}}{T_{\infty}} \frac{\partial^{2} T}{\partial z^{2}}
\end{aligned}
$$

The boundary constraints are followed as $[41,46]$ :

$u=U_{w}, \quad w=W_{0}, \quad T=T_{w}=T_{\infty}+\frac{b r}{1-c t}, \quad C=C_{w}, \quad$ at $\quad z=0$

$u \rightarrow 0, T \rightarrow T_{\infty}, C \rightarrow C_{\infty}$ as $z \rightarrow \infty$

$u$ and $v$ are velocity components of in $\mathrm{r}-\mathrm{z}$ coordinates system. $\beta, \sigma, g, \beta_{T}, D_{B}, D_{T}, \rho, c_{p}, k$ Casson fluid parameter, electrical conductivity, gravity force of acceleration, volumetric coefficient of thermal expansion, effect of Brownian motion, effect of Thermophoresis, the fluid density, the specific heat at constant pressure, and the thermal conductivity of the fluid respectively. $W_{0}=-2\left(\frac{v U_{w}}{r}\right)^{1 / 2}$ expresses the mass transformation parameter with $W_{0}>0$ and $W_{0}<0$ are, suction and injection respectively. Following transforming function are used to dimensionless the Eqs. (1)-(6) as [41]:

and $\varphi(\eta)=\frac{C-C_{\infty}}{C_{w}-C_{\infty}}$
Here "Stokes" function can be expressed as $\psi(r, z)$ with $u=\frac{-1}{r} \frac{\partial \psi}{\partial z}$ and $w=\frac{1}{r} \frac{\partial \psi}{\partial r} \cdot U_{w}=\frac{a r}{1-c t}$ is the stretching velocity with $r$ and $z$-components follows as:

$u=f^{\prime}(\eta)$, and $w=-2 U_{w} \operatorname{Re}^{1 / 2} f(\eta)$,

Reynolds number is defined as $\operatorname{Re}_{r}=\frac{r v_{w}}{v}$, we get the following equations in dimensionless form, the Eqs. (2)-(4) following as:

$\left(1+\frac{1}{\beta}\right) f^{\prime \prime \prime}-M f^{\prime}+2 f f^{\prime \prime}-\left(f^{\prime}\right)^{2}-\alpha\left[f^{\prime}+\frac{1}{2} \eta f^{\prime \prime}\right]+\lambda \theta=0$

$$
\begin{aligned}
& \frac{1}{\operatorname{Pr}} \theta^{\prime \prime}+2 f \theta^{\prime}-f^{\prime} \theta-M f^{\prime}+N_{b} \theta^{\prime} \phi^{\prime}+N_{t}\left(\theta^{\prime}\right)^{2}+E c\left(1+\frac{1}{\beta}\right) f^{\prime \prime 2} \\
& \quad+M E c f^{\prime 2}-\alpha\left[\theta+\frac{1}{2} \eta \theta^{\prime}\right]=0
\end{aligned}
$$

$\phi^{\prime \prime}+\frac{N_{t}}{N_{b}} \theta^{\prime \prime}-S c\left[\alpha\left\{\phi+\frac{1}{2} \eta \phi^{\prime \prime}\right\}+f^{\prime} \phi-2 f \phi^{\prime}\right]=0$

the boundary constraints used in Eqs. (5) and (6) are transformed as [41]: 
Fig. 2 Variation of $\beta$ Casson fluid parameter at a velocity profile, $\mathbf{b}$ temperature profiles and c concentration profiles against $\eta$
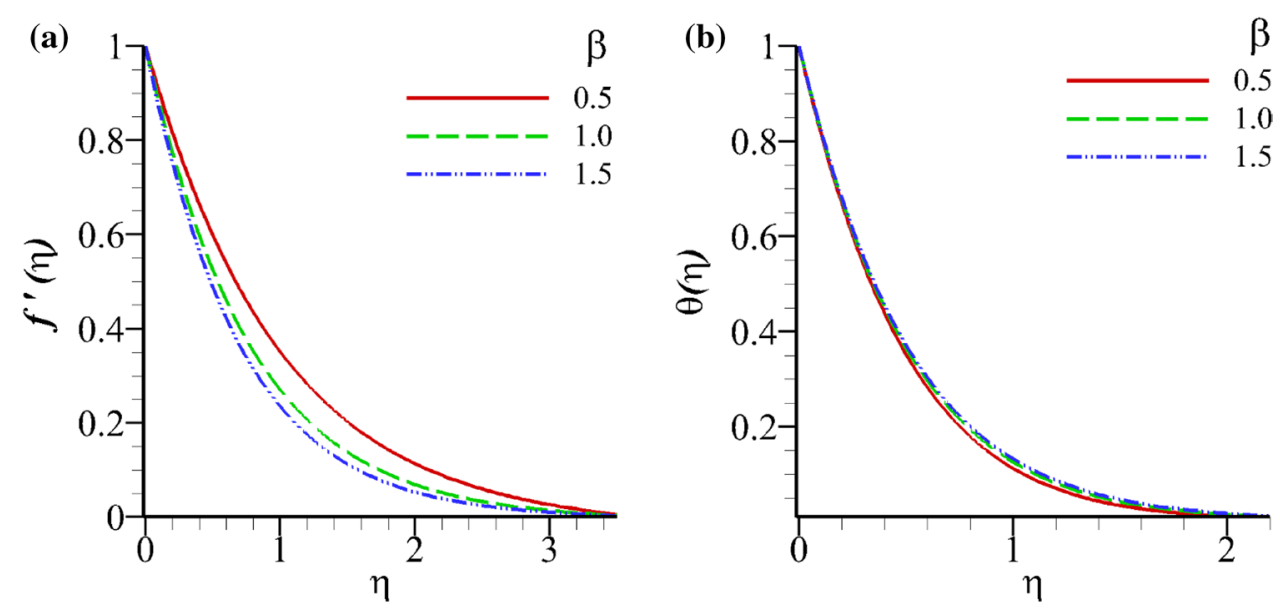

$f(\eta)=S, f^{\prime}(\eta)=1, \theta(\eta)=1, \phi(\eta)=1$, when $\eta=0$

$$
f^{\prime}(\infty)=0, \theta(\infty)=0, \phi(\infty)=0, \text { as } \eta \rightarrow \infty
$$

In Eqs. (9)-(11) the parameters are $\operatorname{Pr}=\frac{\mu c_{p}}{k}, \alpha=\frac{a}{c}, M=\frac{\sigma B^{2}}{\rho_{f}}$, $N_{b}=\frac{\tau\left(C_{w}-C_{\infty}\right) D_{B}}{v}, \quad N_{t}=\frac{\tau\left(T_{w}-T_{\infty}\right) D_{T}}{v T_{\infty}}, \quad S c=\frac{v}{D_{B}}, \quad \lambda=\frac{G r}{R e^{2}}$, $G r=\frac{g \beta\left(T_{w}-T_{\infty}\right) r^{3}}{v^{2}}, E C=\frac{u_{w}^{2}}{c_{p}\left(T_{w}-T_{\infty}\right)}$, and $S,\{S>0, S<0\}$ represent Prandtl, Unsteady, magnetic field flux, Brownian motion, Thermophoresis, Schmidt number, mixed convection parameter, Grashof, Eckert number and the mass transfer for mass suction and injection respectively. The physical quantities like skin coefficient $C_{f}$, local Nusselt number Nu and Sherwood number Sh are defined as:

$$
C_{f}=\frac{\tau_{w}}{\frac{1}{2} \rho U^{2}}, \quad N_{u}=\frac{r p_{w}}{K\left(T_{w}-T_{\infty}\right)} \quad \text { and } \quad S h=\frac{r q_{m}}{D_{B}\left(C_{w}-C_{\infty}\right)}
$$

where $\tau_{w}$ is the skin friction along the r direction, the heat and mass transfer from the surfaces $p_{w}$ and $q_{m}$ are given by

$\tau_{w}=\left(\mu_{B}+\frac{P_{y}}{\sqrt{2 \pi c}}\right)\left(\frac{\partial u}{\partial z}\right)_{z=0}, \quad p_{w}=-k\left(\frac{\partial T}{\partial z}\right)_{z=0} \quad$ and $\quad q_{m}=-D_{B}\left(\frac{\partial C}{\partial y}\right)_{z=0}$.

The dimension free variables explained in Eqs. (7), (8) and these well-quantities as:

$\operatorname{Re}_{r}^{1 / 2} C_{f}=\left(1+\frac{1}{\beta}\right) f^{\prime \prime}(0), \quad \operatorname{Re}_{r}^{-1 / 2} N u=-\theta^{\prime}(0) \quad$ and $\quad \operatorname{Re}_{r}^{-1 / 2} S h=-\varphi^{\prime}(0)$. 
Fig. 3 Variation of $M(\mathrm{MHD})$ parameter at a velocity profile, b temperature profiles and $\mathbf{c}$ concentration profiles against $\eta$
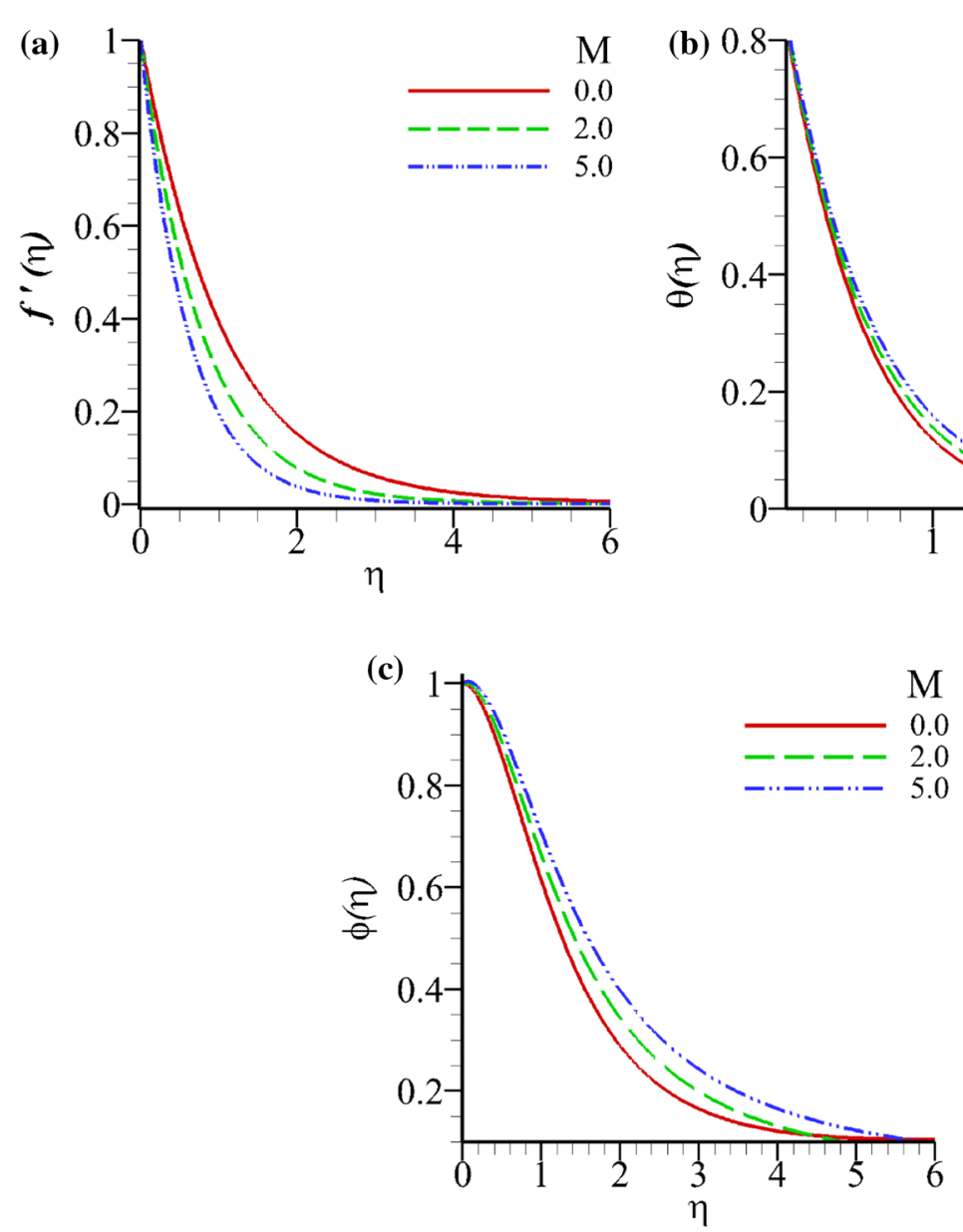

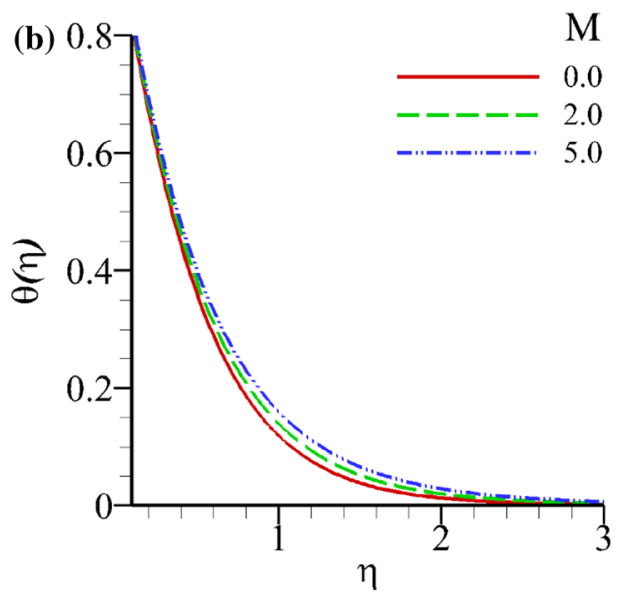

$\mathrm{M}$

$M$

.

\subsection{Finite difference solutions}

In this method, first of all, the new variables $U, V, G, P, W$ and $Q$ are introduced to convert Eqs. (10)-(12) into a set of first order differential equations.

A net on $\eta$ is then introduced which is defined as follow

$\eta_{0}=0, \eta_{j}=\eta_{j-1}+h_{j}, \quad j=1,2,3, \ldots, J$

The variable quantities $(P, G, Q, f, U, V, W)$ at different points on the net $\eta_{j}$ are then estimated by $\left(P_{j}^{n}, G_{j}^{n}, Q_{j}^{n} f_{j}^{n}, U_{j}^{n}\right.$, $\left.V_{j}^{n}, W_{j}^{n}\right)$ and $g_{j}^{n}$ is also exerted for quantities halfway between net points

$$
\begin{aligned}
& \eta_{j}=\frac{1}{2}\left(\eta_{j}+\eta_{j-1}\right) \\
& g_{j}^{n-1 / 2}=\frac{1}{2}\left(g_{j}^{n}+g_{j}^{n-1}\right)
\end{aligned}
$$

We substitute the finite difference estimation of the derivatives in the first order set of differential equations along with the boundary conditions. Now Newton's quasi-linearization method is employed to linearize the system of discretized equations involving $7 J+7$ unknowns of the form $f_{j}^{n}, U_{j}^{n}, V_{j}^{n}, G_{j}^{n}, P_{j}^{n}, W_{j}^{n}, Q_{j}^{n}$ and Keller-box elimination technique is utilized to attain the solution of these equations.

To begin the procedure, we recommend a set of estimated profiles for $f, U, V, G, P, W$ and $Q$ which are implemented in Keller box scheme with accuracy of $2^{\text {nd }}$ order to move step by step. This repetitive process cease at the final velocity, temperature and concentration functions when the difference in calculating these functions in the successive procedure is less than $10^{-5}$, i.e. $\delta f_{i} \leq 10^{-5}$. We consider $\eta_{j}=\sinh \left(\frac{j}{a}\right)$ attaining the rapid convergence 
Fig. 4 Variation of $\alpha$ unsteady parameter at a velocity profile, b temperature profiles and $\mathbf{c}$ concentration profiles against $\eta$
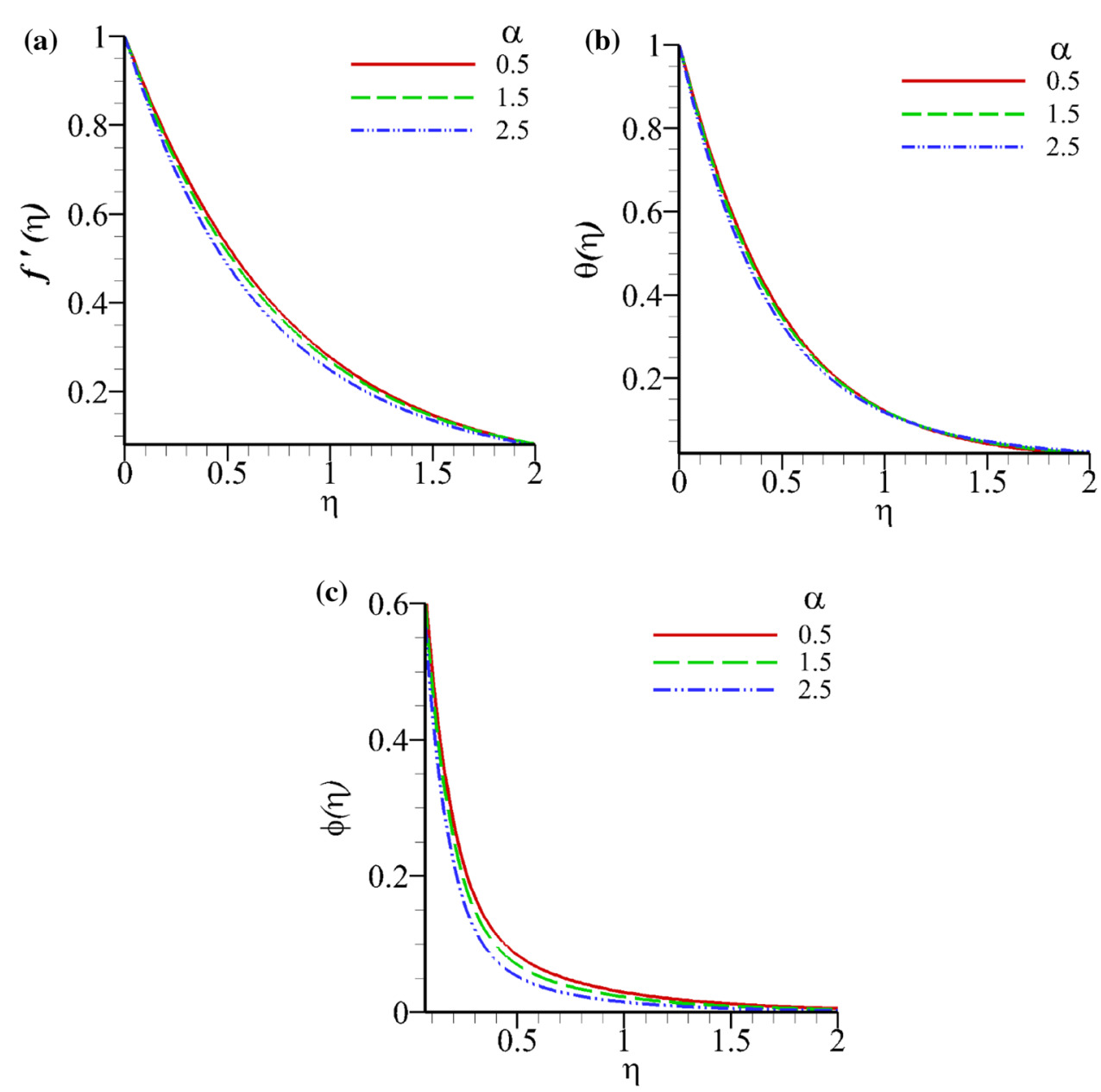

and hence making the computations time and space economical.

\section{Results and discussion}

MHD Axisymmetric Casson nanofluid free convection flow and heat transmission over unsteady radially stretching sheet is proposed. The impacts of different parameters on flow features are sketched graphically and results of study are tabulated and argued briefly.
The governing transport Eqs. (9)-(11) have been solved by utilizing KBM (Keller Box Method) and sketched in the Figs. $2,3,4,5,6,7,8,9,10,11,12$ and 13 . The numerical problem is comprised of three dependent thermosfluid-dynamic-variable $(f, \theta, \phi)$ and eight multi-physical control parameters $\mathrm{Pr}, \mathrm{Sc}, \beta, M, N_{b}, N_{t} \alpha, \lambda$. The effects of stream wise space variables $\eta$ are also explored. A comparison of numerically obtained results is established for reduced Nusselt number with existing works for $M=\lambda=\mathrm{Sc}=N_{t}=N_{b}=0, \beta=\infty$. Tables 1,2 and 3 show a well justifying comparisons of our results and [41,47] results for $f^{\prime \prime}(0)$ and $-\theta(0)$. 
Fig. 5 Variation of $\lambda$ mixed convection parameter at a velocity profile, $\mathbf{b}$ temperature profiles against $\eta$ profiles and c concentration
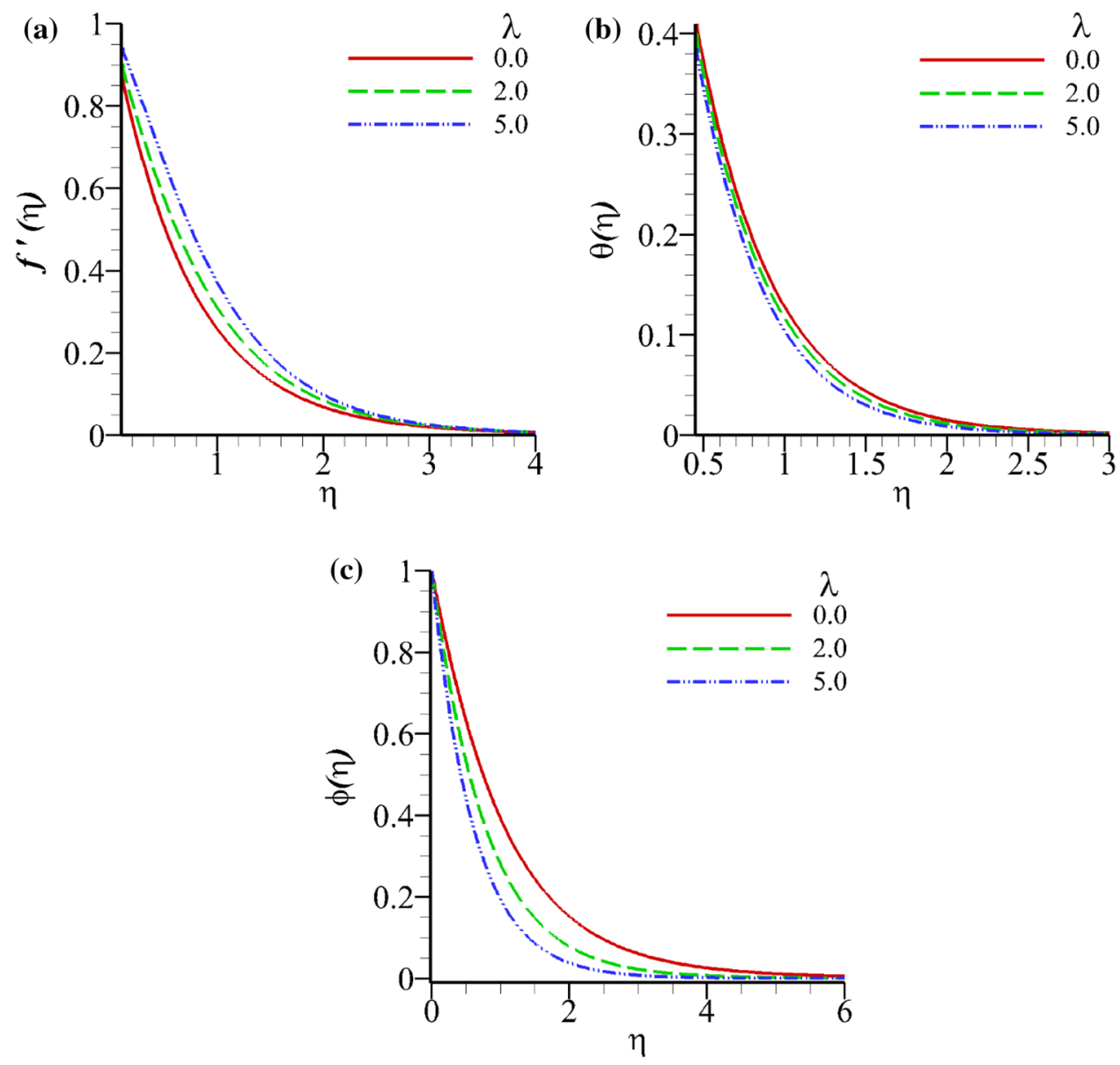

Table 4 presents the variations of $f^{\prime \prime}(0),-\theta^{\prime}(0)$ and $-\phi^{\prime}(0)$, for various values of influential flow parameters. A decline in Nusselt number is witnessed while Sherwood number increase with the rise in $\mathrm{Pr}$ and $\mathrm{Sc}$. The variations in Nusselt number can be demonstrated on the basis that by increasing the values of $N_{b}$ or $N_{t}$ results a rise in thermal boundary layer and thus a reduction of Nusselt number. However, the Sherwood number augments significantly with the rise in $N_{b}$ and $N_{t}$.

\subsection{Velocity profile}

Figure 2a shows that when we increase the Casson fluid parameter $\beta$, it changes the fluid nature from non-Newtonian to Newtonian. As momentum diffusivity of non-Newtonian fluid is faster as compare to Newtonian fluid, therefore both radial velocity and momentum boundary layer shows reduction with rising values of parameter $\beta$. Similar patterns for unsteady fluid flow can be seen in [41]. Figure $3 a$ illustrates the impacts of parameter $M$ on the dimension free velocity. It can be noticed that higher values of 
Fig. 6 Variation of $S$ mass suction at a velocity profile, b temperature profiles and $\mathbf{c}$ concentration profiles against $\eta$
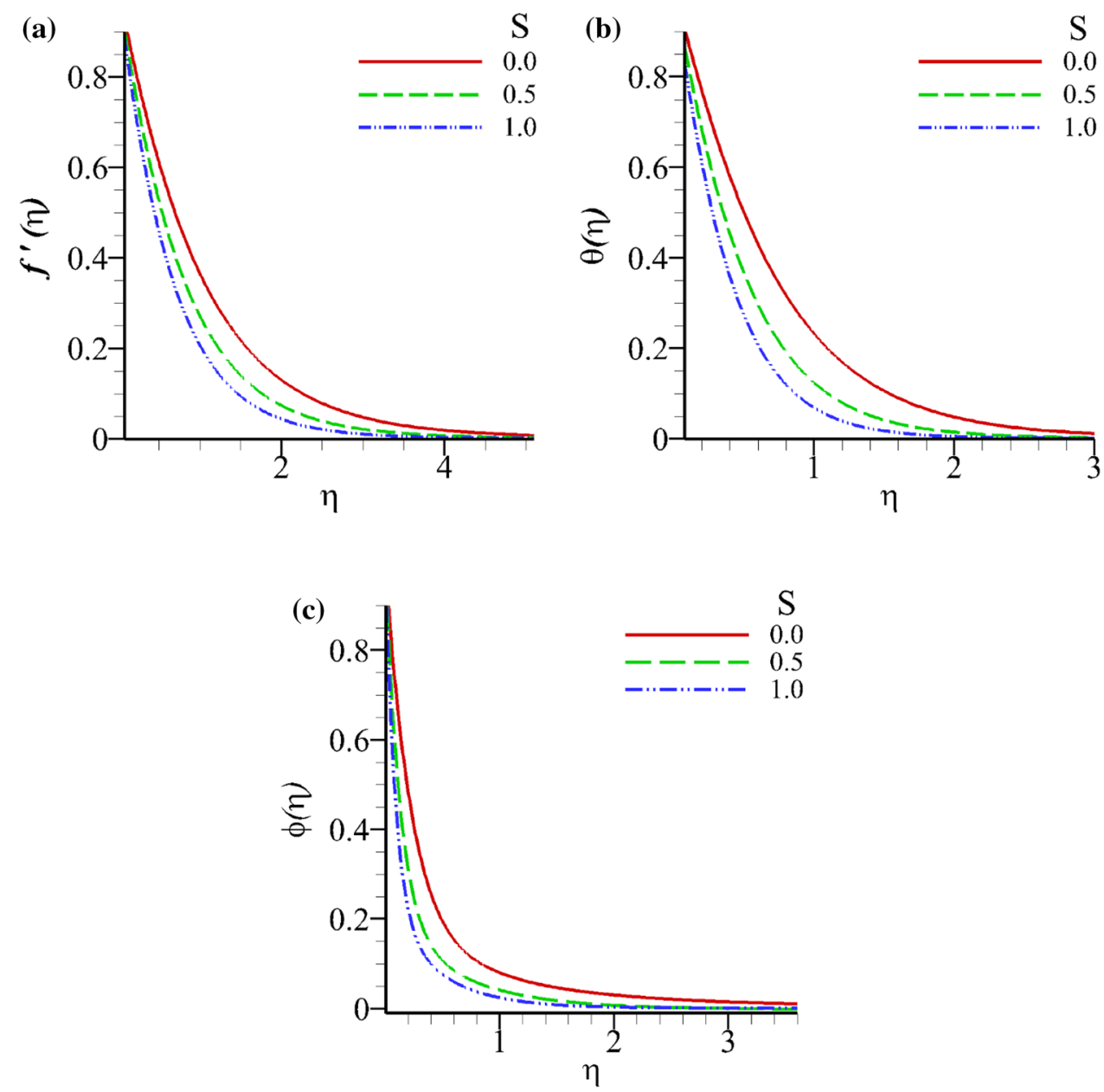

$M$ offers a resistive force to an electrically conducting fluid which as a consequence slow down the movement and hence a decline in velocity is observed. Figure $4 a$ exhibits a decline in velocity profile and boundary layer thickness with the rise in value of unsteady parameter $a$. It is noticed that increase in value of $\alpha$ slow down the movement of boundary layer thickness and hence a decline in velocity is observed. Figure 6 a reveals a reduction in both profiles with the rise in suction parameter $(S>0)$ while Fig. 7a displays an opposite behavior with decreasing values of injection parameter $(S<0)$. Figure 5a illustrates that there is a direct relationship between mixed Convection parameter $\lambda$ and velocity profile. Figure 9 a indicates an elevation in both profiles with the enhancement in thermophoresis parameter $N_{t}$ and Brownian motion $N_{b}$.

The fluctuations of the shear stress, is delineated in Fig. 11a for different Pr values. The local skin friction increases alongside the increase in $\lambda$ value. It is because of the positive correlation between the fluid velocity and buoyancy force, which elevates the wall shear stress leading to increase the coefficient of skin-friction. For a unique $\lambda$ with increasing Pr, the coefficient of skin-friction 
Fig. 7 Variation of $S$ injection at $\mathbf{a}$ velocity profile, $\mathbf{b}$ temperature profiles and c concentration profiles against $\eta$
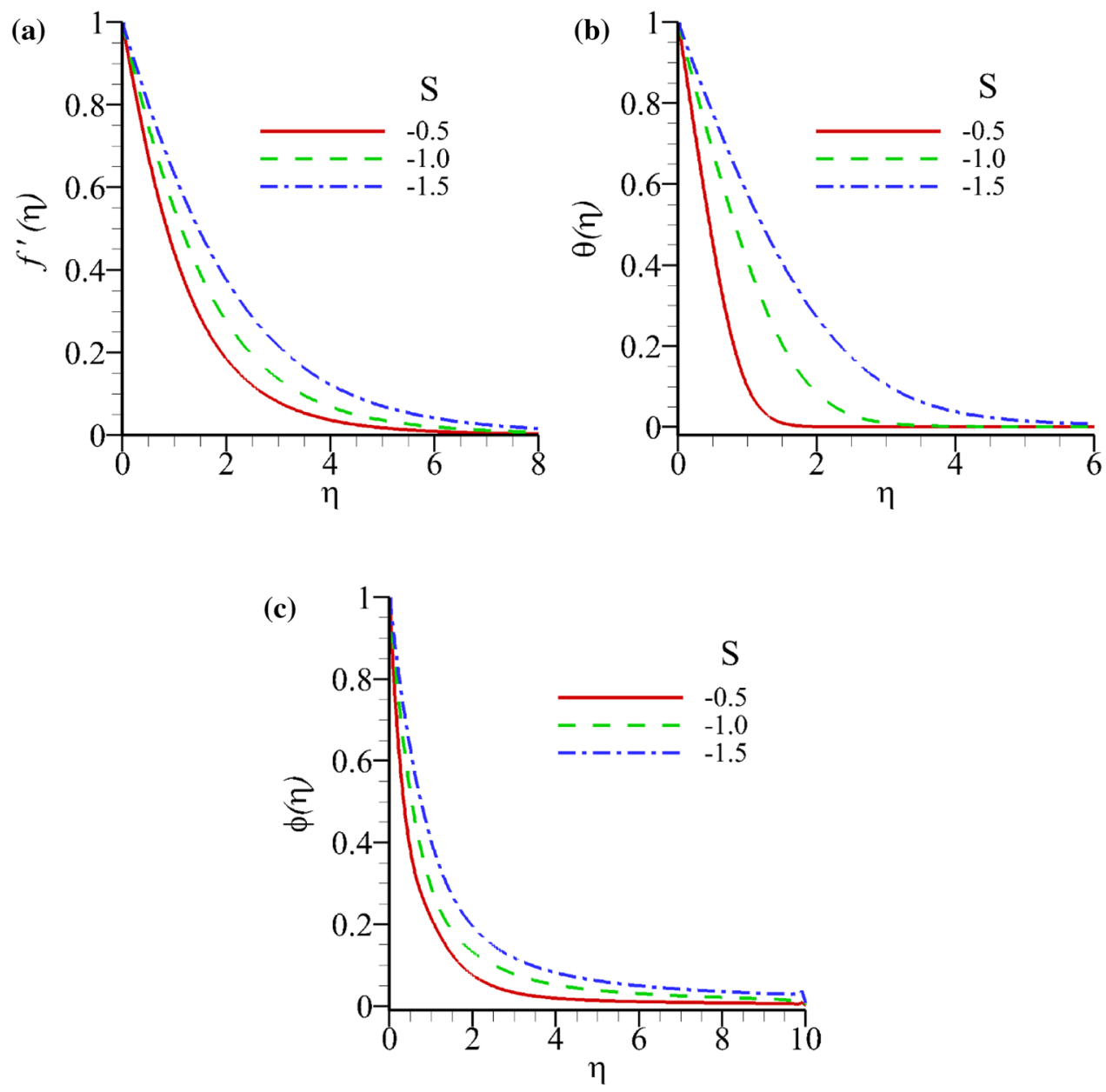

Fig. 8 Variation of Pr Prandtl number at a temperature profiles and $\mathbf{b}$ concentration profiles against $\eta$

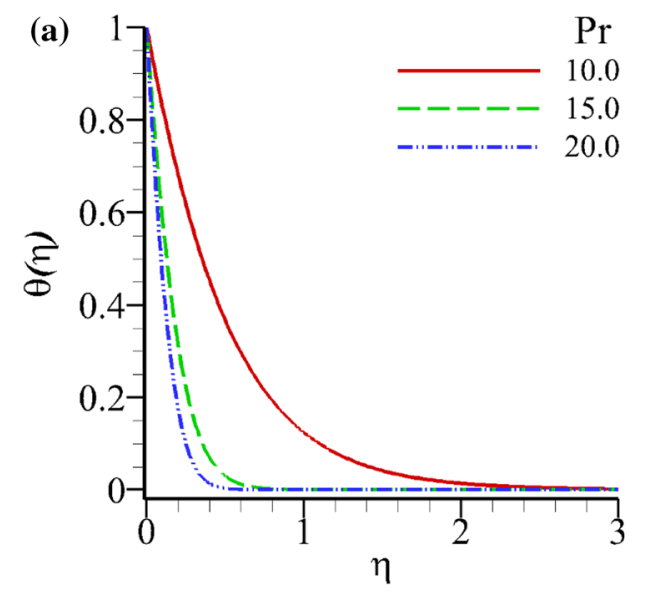

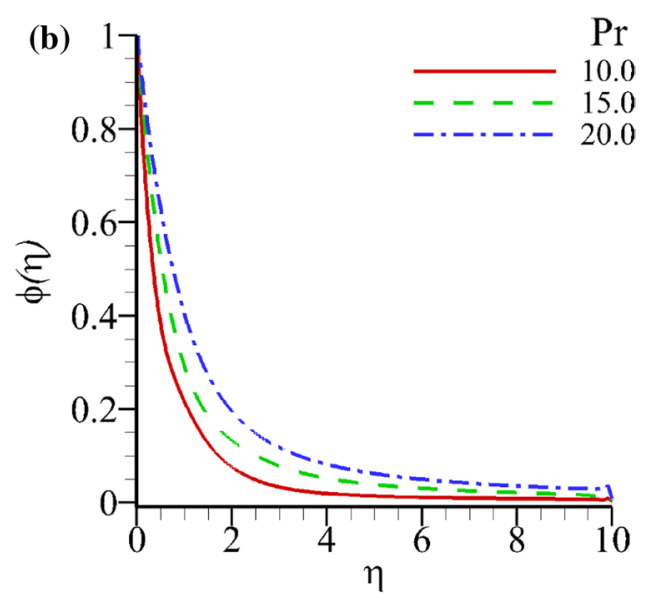


Fig. 9 Variation of $N_{t}, N_{b}$ at a temperature profiles and $\mathbf{b}$ concentration profiles against $\eta$

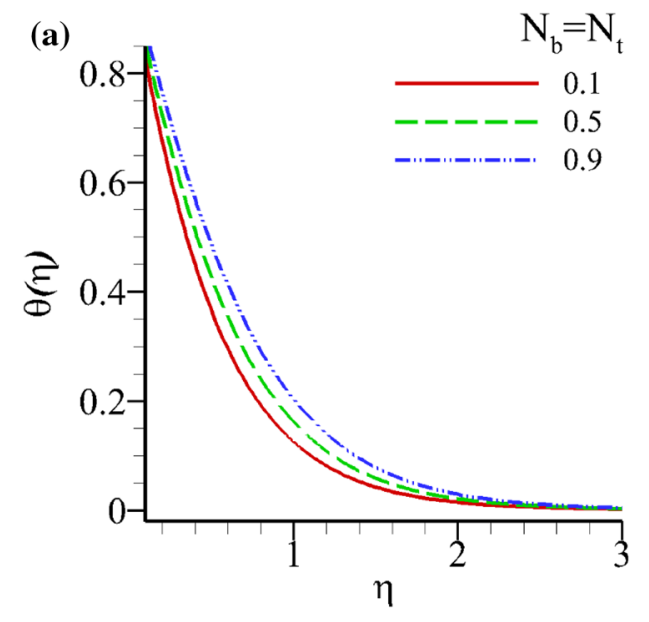

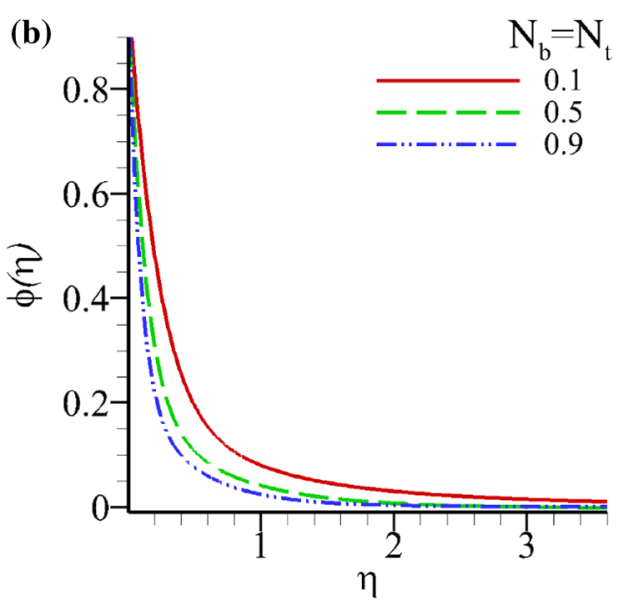

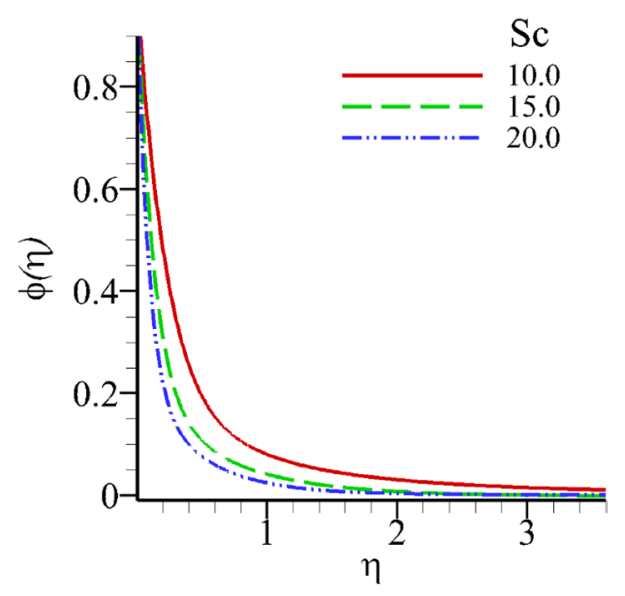

Fig. 10 Variation of Sc Schmidt number at c concentration profiles against $\eta$

decrease. Figure 12a shows that rise in the values of $N_{b}$ and $N_{t}$, results a decrease in the shear stress. There is an increase skin friction coefficient with the rising values of suction parameter and can be seen in Fig. 13a. From Fig. 14a, it is shown that there is a decline in skin friction coefficient with the increasing values of Magnetic parameter.

\subsection{Temperature profile}

Figure $4 b$ shows that rise in unsteady parameter $a$ results a decline of dimension-less temperature profile and thermal boundary layer thickness. Figure $5 \mathrm{~b}$ exhibits that the higher values of radially stretching bouncy force reduces the thermal boundary layer thickness and temperature profile. A noticeable decrease in temperature along the boundary layer with rise in $\lambda$ values is witnessed due to which the fluid flow regime is cooled most effectively at stretchable sheet and gets hot as we move along the stretchable surface boundary upwards. Figure $6 \mathrm{~b}$ shows reduction in thermal boundary layer thickness because of elevation in mass suction parameter $(S>0)$. Figure 8a depicts the radial temperature profile in which the boundary layer thickness is reduced with the rise in Prandtl number Pr. Casson fluid includes in the present investigation 
Fig. 11 Variation of Pr at a skin coefficient $C_{f}$, b local Nusselt number $\mathrm{Nu}$, and $\mathbf{c}$ Sherwood number Sh at $\lambda$
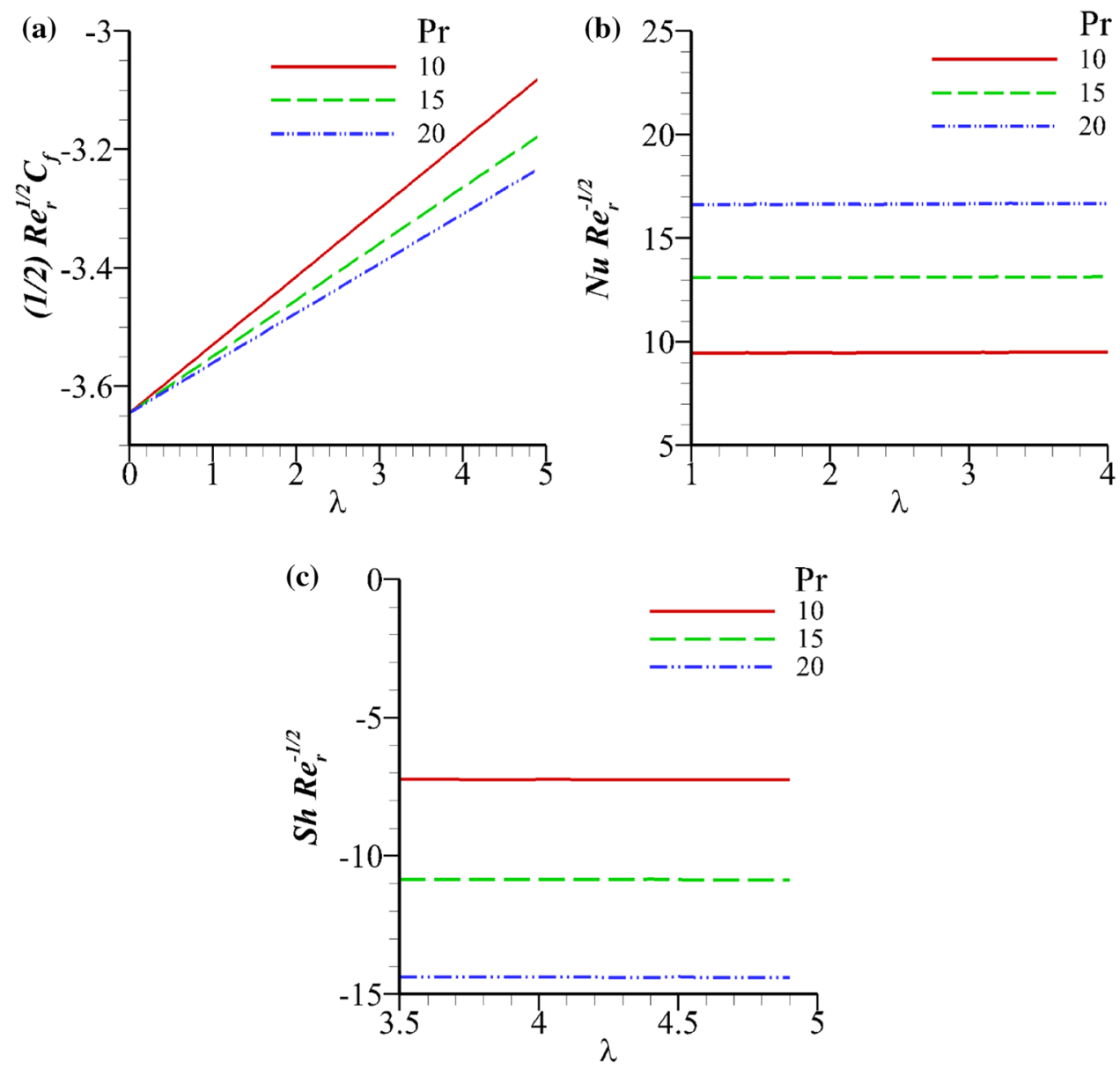

exhibits great viscosity and Prandtl number is used to increase the rate of cooling in conducting flows. This is because the Pr number is defined as the ratio between momentum and thermal diffusivity. In the present investigation $\operatorname{Pr}=20$ is very suitable for cooling purposes.

Figure $2 \mathrm{~b}$ demonstrates that thermal boundary layer and temperature shoot up with higher values of $\beta$. Figure $3 \mathrm{~b}$ display the similar impact on both profiles with magnetic parameter $M$. Figure 7a illustrate a rise in boundary layer thickness with the injection parameter $S<0$. Figure 8 a exhibits that by increasing in $\operatorname{Pr}$ values consequently diminishes the temperature. Hence the Prandtl number can be utilized to raise the cooling rate in conducting flows. Fig 9a shows the impacts of Brownian motion and Thermophoresis on temperature distribution profile. As $N_{b}, N_{t}$ start increasing at a point, the temperature is increased. Consequently the boundary layer thickness rises with the rise in values of $N_{b}, N_{t}$. 
Fig. 12 Variation of $N_{b}=N_{t}$ at a skin coefficient $C_{f}$, b local Nusselt number $\mathrm{Nu}$, and $\mathbf{c}$ Sherwood number Sh at $\lambda$
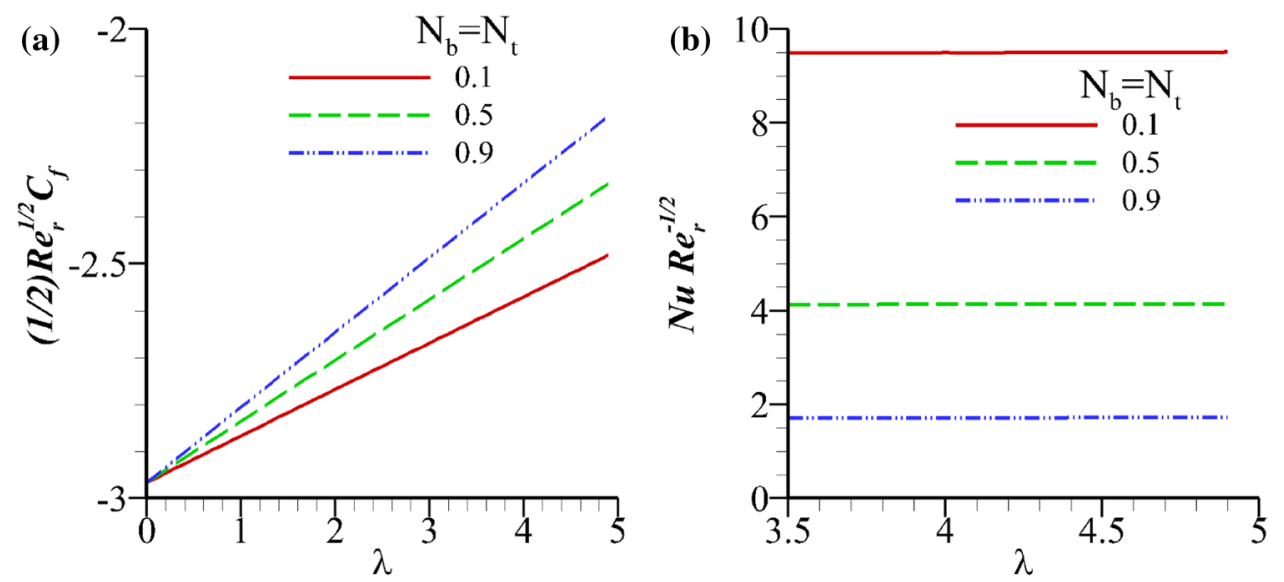

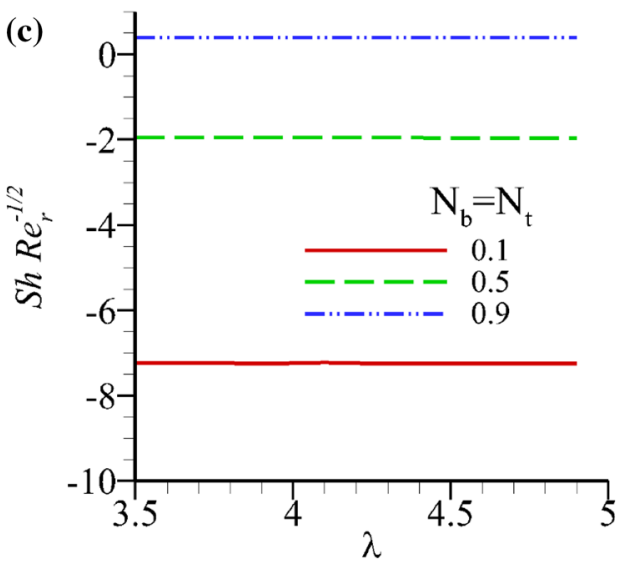

It is noted that the velocity tends to increase due to increased buoyancy force and causes the wall shear stress to increase and thus there is an increase in heat transfer at the sheet and it can be been in Fig. 11b. We observe that with the increase in both $N_{b}$ and $N_{t^{\prime}}-\theta^{\prime}(0)$ decreases Fig. 12b. This behavior can be explained in the sense that increasing the Brownian motion or that of thermophoresis parameters cause to decrease the Nusselt number. Figure $13 \mathrm{~b}$ shows that skin friction coefficient decreases when suction increases. It is observed in Fig. 14b, an increase in Magnetic parameter decrease the Nusselt Number.

\subsection{Concentration profile}

Figure $2 c$ displays an elevation in concentration profile and concentration boundary layer thickness with higher values of Casson fluid parameter $\beta$.The effect of dimensionless magnetic parameter $M$ on concentration profile 
Fig. 13 Variation of Sc at a skin coefficient $C_{f}$, b local Nusselt number $\mathrm{Nu}$, and $\mathbf{c}$ Sherwood number Sh at $\lambda$
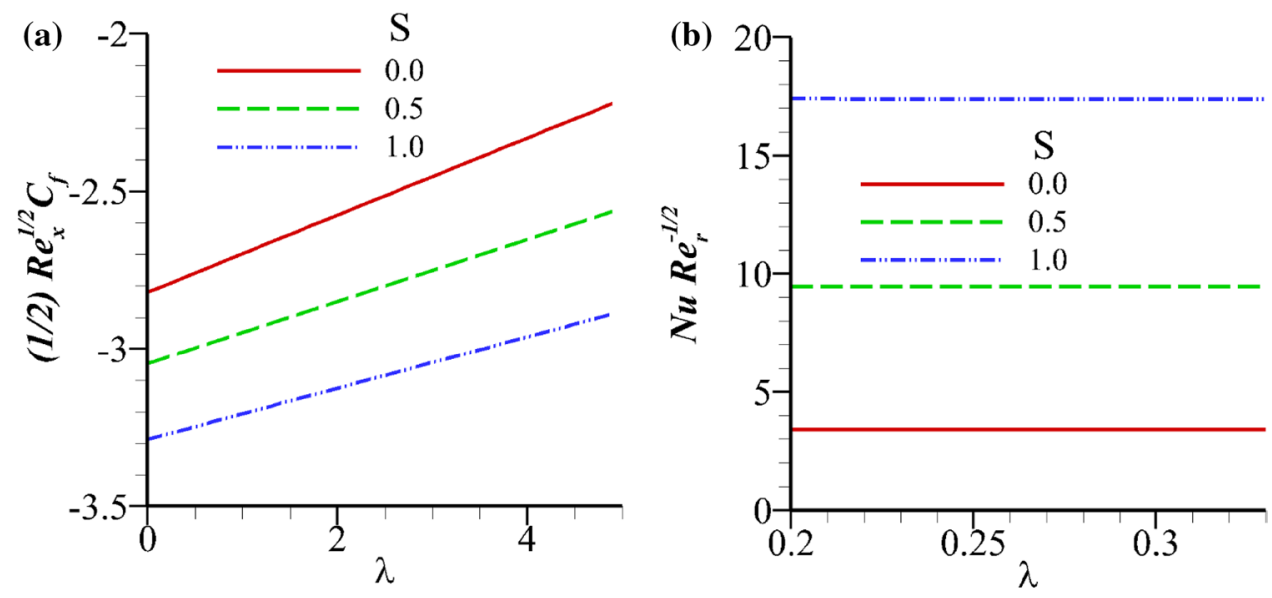

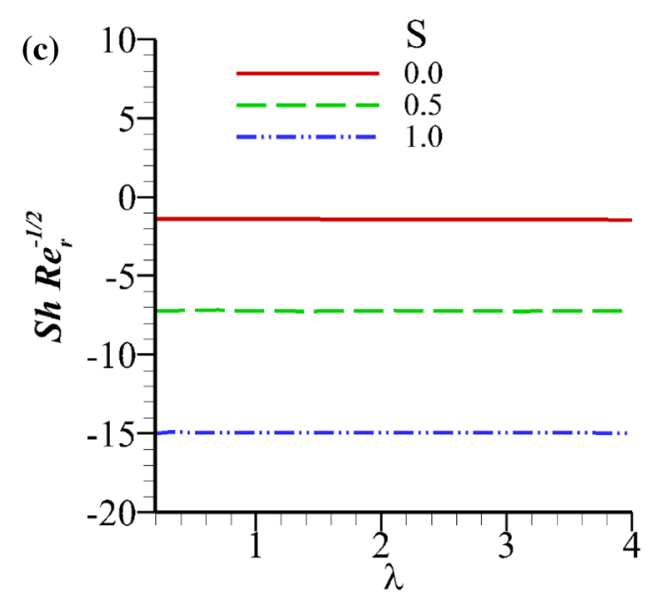

Table 1 Comparison of results for $f^{\prime \prime}(0)$ when $M=\lambda=S c=N_{t}=N_{b}=0, \quad \beta=\infty$ for different values

\begin{tabular}{llll}
\hline$S$ & $\alpha$ & {$[41]$} & Present results \\
\hline-1.0 & 0.5 & -0.620400 & -0.620400 \\
-0.5 & & -0.887200 & -0.887200 \\
0.0 & & -1.308999 & -1.308998 \\
0.5 & & -1.907999 & -1.907999 \\
1.0 & & -2.655999 & -2.655999 \\
0.5 & 0 & -1.798999 & -1.798998 \\
& 0.5 & -1.907999 & -1.907999 \\
& 1.0 & -2.016999 & -2.016999 \\
\hline
\end{tabular}

is sketched in Fig. 3c. It demonstrates that concentration profile is higher with higher values of $M$. Figure $4 c$ exhibits the relationship between unsteady parameter $a$ and concentration profile. It depicts that concentration profile decreases with the rise in unsteady parameter $a$. Figure $5 c$ elucidates that concentration profile and thickness of concentration boundary layer augment with an elevation in values of $\lambda$. Figure $6 c$ shows a sharp decline in concentration profile due to increase in mass suction parameter
Table 2 Comparison of results for $-\theta^{\prime}(0)$ when $M=\lambda=S c=N_{t}=N_{b}=0, \beta=\infty$ for different values

\begin{tabular}{lllll}
\hline$\alpha$ & $S$ & $\operatorname{Pr}$ & {$[41]$} & Present results \\
\hline 0.0 & 0.5 & 1 & -1.798999 & -1.798999 \\
0.5 & & & -1.907999 & -1.907999 \\
1.0 & & & -2.016999 & -2.016999 \\
0.5 & -1.0 & & -0.620400 & -0.620400 \\
& -0.5 & & -0.887200 & -0.887200 \\
& 0.0 & & -1.308999 & -1.308999 \\
& 0.5 & & -1.907999 & -1.907998 \\
& 1.0 & & -2.655999 & -2.655999 \\
0.5 & 0.5 & 0.5 & -1.119999 & -1.119999 \\
& & 0.7 & -1.45000 & -1.450001 \\
& & 1 & -1.907999 & -1.907999 \\
\hline
\end{tabular}

$S>0$ but Fig. 7c shows opposite behavior in case of injection parameter $S<0$. It enhances value of nanoparticle volume fraction. The relation between PrandtI number $\mathrm{Pr}$ and nanoparticle volume fraction concentration profile is displayed in Fig. 8b. It narrates that higher value of Prandtl number increases the nano-particle concentration. It is 
Table 3 The numerical values of the skin friction coefficient for different values of physical parameter $\lambda=S c=N_{t}=N_{b}=0, \beta=\infty$. are fixed

\begin{tabular}{lllll}
\hline$\alpha$ & $M$ & $S$ & $\begin{array}{c}-\frac{1}{2} \operatorname{Re} \frac{1}{n+1} C_{f} \\
(\mathrm{n}=1)[47]\end{array}$ & Present results \\
\hline 0.0 & 1.0 & 0.2 & 1.75664 & 1.75654 \\
0.2 & & & 1.79894 & 1.79895 \\
0.5 & & & 1.86166 & 1.86166 \\
0.2 & 0.0 & & 1.45257 & 1.45250 \\
& 0.5 & & 1.63582 & 1.63581 \\
& 1.0 & 0.0 & 1.79894 & 1.79894 \\
& & 0.2 & 1.58058 & 1.58055 \\
& & 0.5 & 1.79894 & 1.79860 \\
& & & 2.16993 & 2.16982 \\
\hline
\end{tabular}

witnessed that concentration profile increase away from the wall but decreases close to the wall. The same situations can be witnessed in case of Brownian motion and the Thermophoresis $N_{b}, N_{t}$ in Fig. 9b. Figure 10a indicates that $\mathrm{Schmidt}$ number $\mathrm{Sc}$ reduces the nanoparticle volume fraction concentration profile.

From Fig. $11 \mathrm{c}$ it is observed that the rate of mass transfer decreases with the increase of Pr. The Sherwood number increases with increasing values of $N_{b}$ and $N_{t}$, it can be seen in Fig. 12c. From Fig. 13a-c show that skin friction coefficient decreases, Nusselt number increases and Sheerwood number decrease with the increase of suction parameter. Figure $14 \mathrm{c}$ shows that an increase in Magnetic parameter decreases the rate of mass transfer.
Table 4 Variations in $f^{\prime \prime}(0),-\theta^{\prime}(0)$, and $-\phi^{\prime}(0)$, for various values of the flow parameters

\begin{tabular}{|c|c|c|c|c|c|c|c|c|c|c|c|}
\hline $\operatorname{Pr}$ & $N_{b}$ & $N_{t}$ & Sc & $\alpha$ & $M$ & $\beta$ & $\lambda$ & $S$ & $f^{\prime \prime}(0)$ & $-\theta^{\prime}(0)$ & $-\phi^{\prime}(0)$ \\
\hline 1 & 0.1 & 0.1 & 1 & 0.5 & 0.5 & 0.5 & 0.5 & 0.5 & -2.98021 & 1.93918 & 0.01065 \\
\hline 10 & & & & & & & & & -3.11126 & 10.44424 & -8.25367 \\
\hline 15 & & & & & & & & & -3.12165 & 14.52463 & -12.30713 \\
\hline 20 & & & & & & & & & -3.12759 & 18.49047 & -16.25695 \\
\hline \multirow[t]{24}{*}{1.0} & 0.1 & 0.1 & & & & & & & -2.98021 & 1.93918 & 0.01065 \\
\hline & 0.5 & 0.5 & & & & & & & -2.96017 & 1.56091 & 0.36065 \\
\hline & 0.9 & 0.9 & & & & & & & -2.93977 & 1.25533 & 0.63892 \\
\hline & & & 10 & & & & & & -2.97958 & 1.83443 & 6.46349 \\
\hline & & & 15 & & & & & & -2.97986 & 1.81910 & 9.35633 \\
\hline & & & 20 & & & & & & -2.98036 & 1.81399 & 12.01931 \\
\hline & & & 1.0 & 0.5 & & & & & -2.98021 & 1.93918 & 0.01065 \\
\hline & & & & 1.5 & & & & & -3.34983 & 2.10801 & 0.45865 \\
\hline & & & & 2.5 & & & & & -3.69835 & 2.28007 & 0.72770 \\
\hline & & & & 0.5 & 0.0 & & & & -2.69195 & 1.95275 & 0.02727 \\
\hline & & & & & 2.0 & & & & -3.71890 & 1.90481 & -0.02948 \\
\hline & & & & & 5.0 & & & & -4.86555 & 1.85344 & -0.07693 \\
\hline & & & & & 0.5 & 0.5 & & & -2.98021 & 1.93918 & 0.01065 \\
\hline & & & & & & 1.0 & & & -2.50431 & 1.90127 & -0.03292 \\
\hline & & & & & & 1.5 & & & -2.32389 & 1.88140 & -0.05411 \\
\hline & & & & & & & 0.0 & & -2.49438 & 1.86935 & -0.06462 \\
\hline & & & & & & & 2.0 & & -1.83234 & 1.91334 & -0.02859 \\
\hline & & & & & & & 5.0 & & -0.91391 & 1.96616 & 0.01061 \\
\hline & & & & & & 1.5 & & 0.0 & -1.73063 & 1.29302 & 0.36535 \\
\hline & & & & & & & & 0.5 & -2.32389 & 1.88140 & -0.05411 \\
\hline & & & & & & & & 1.0 & -2.88293 & 2.44790 & -0.46932 \\
\hline & & & & & & & & -0.5 & -1.27281 & 0.87177 & 0.59329 \\
\hline & & & & & & & & -1.0 & -1.00249 & 0.64939 & 0.64467 \\
\hline & & & & & & & & -1.5 & -0.72586 & 0.44861 & 0.60584 \\
\hline
\end{tabular}


Fig. 14 Variation of $M$ at a skin coefficient $C_{f}$, b local Nusselt number $\mathrm{Nu}$, and $\mathbf{c}$ Sherwood number Sh at $\lambda$
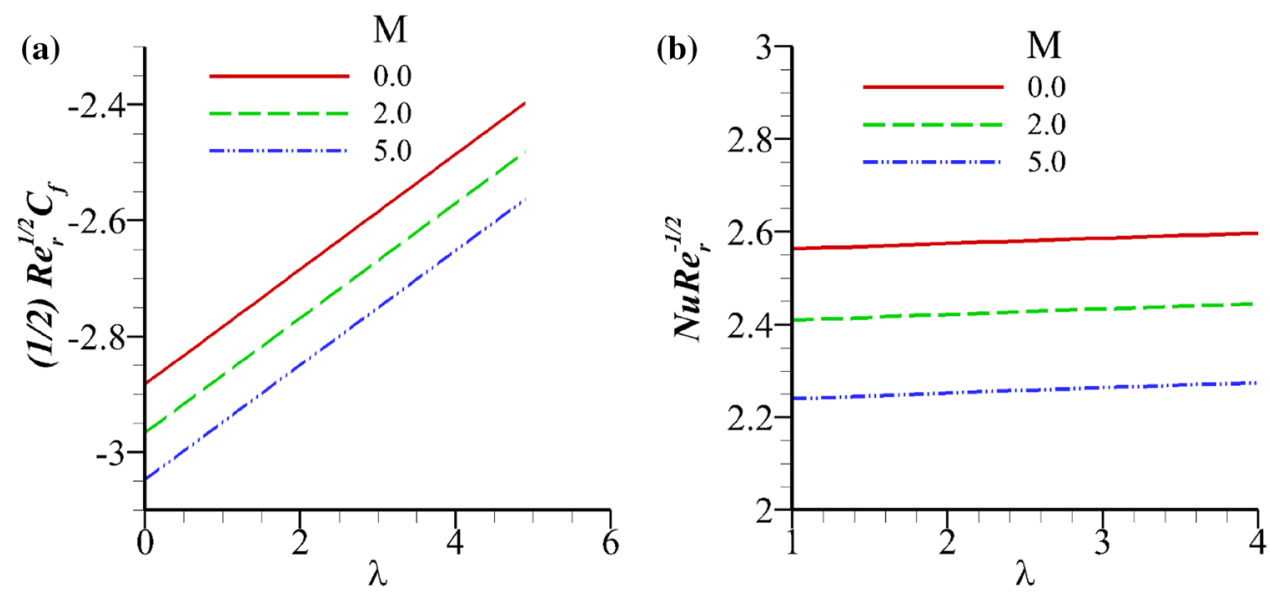

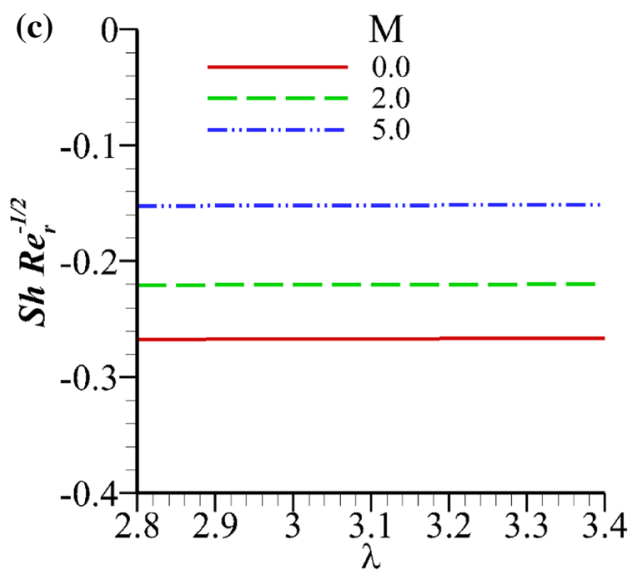

\section{Conclusions}

Unsteady axisymmetric Casson fluid flow of free convection with nano-particles over a radially stretching surface is studied. The numerical results are sketched, examined and argued briefly. The solution mainly relies on the nanoparticle volume fraction, linear radially stretching parameter, and the Prandtl number. Present results are compared with the previous work done by Shahzad et al. [41] and a good agreement is found. It is noticed that the insertion of nanoparticles into the base fluid of current investigation is able to change the flow pattern.

The major results of study are as under:

1. Rise in Casson fluid parameter $\beta$ creates resistance in the flow of fluid due to which fluid velocity is decreased.

2. Velocity profile augments with the rise in MHD parameter $M$.

3. Decline in velocity, temperature and concentration profile is witnessed with the rise in unsteady parameter and hence the heat and mass transmission is reduced.
4. Free convection and velocity varies directly.

5. Decrease in the suction parameter $S>0$ reduces the velocity, temperature and concentration profile closed to the wall.

6. The rise in the injection parameter causes a rise in velocity and concentration profile but a sharp enhancement in temperature profile.

7. Temperature profile declines with the rise in $\mathrm{Pr}$, while concentration profile initially increases and then decrease continuously.

8. By increasing the Brownian motion parameter and Thermophoresis, the temperature of the fluid rises but concentration profile decreases in start and then start increasing.

9. Reduction in concentration profile is noted with the rise in Sc parameter.

Acknowledgements We are grateful to the Chinese government scholarship council (CSC) for the scholarship award. Also, thankful to Professor Yong Xu for his continued guidance throughout the work. 


\section{Compliance with ethical standards}

Conflict of interest The authors declare that they have no conflict of interest.

\section{References}

1. Metzner AB, Otto RE (1957) Agitation of non-Newtonian fluids. AIChE J 3(1):3-10

2. Parand K, Fotouhifar M, Yousefi H, Delkhosh M (2019) A rational approximation to the boundary layer flow of a non-Newtonian fluid. J Braz Soc Mech Sci Eng 41(3):125

3. Casson N (1959) A flow equation for pigment-oil suspensions of the printing ink type. In: Mill DC (ed) Rheology of disperse systems. Pergamon Press, Oxford, pp 84-102

4. Scott Blair GW (1959) An equation for the flow of blood, plasma and serum through glass capillaries. Nature 183:613

5. Charm S, Kurland G (1965) Viscometry of human blood for shear rates of $0-100,000 \mathrm{sec}^{-1}$. Nature 206:617

6. Merrill EW, Benis AM, Gilliland ER, Sherwood TK, Salzman EW (1965) Pressure-flow relations of human blood in hollow fibers at low flow rates. J Appl Physiol 20(5):954-967

7. Makinde OD, Sandeep N, Ajayi TM, Animasaun IL (2018) Numerical exploration of heat transfer and Lorentz force effects on the flow of MHD Casson fluid over an upper horizontal surface of a thermally stratified melting surface of a paraboloid of revolution. Int J Nonlinear Sci Numer Simul 19(2/3):93-106

8. Gireesha BJ, Archana M, Prasannakumara BC, Gorla R, Makinde OD (2017) MHD three dimensional double diffusive flow of Casson nanofluid with buoyancy forces and nonlinear thermal radiation over a stretching surface. Int J Numer Meth Heat Fluid Flow 27(12):2858-2878

9. Hari Krishna Y, VenkataRamana Reddy G, Makinde OD (2018) Chemical reaction effect on MHD flow of Casson fluid with porous stretching sheet. Defect Diffus Forum 389:100-109

10. Makinde OD, Nagendramma V, Raju CSK, Leelarathnam A (2017) Effects of Cattaneo-Christov heat flux on Casson nanofluid flow past a stretching cylinder. Defect and Diffusion Forum 378:28-38

11. Ibrahim W, Makinde OD (2016) Magnetohydrodynamic stagnation point flow and heat transfer of Casson nanofluid past a stretching sheet with slip and convective boundary condition. J Aerosp Eng 29(2):04015037

12. Tamoor M, Waqas M, Khan MI, Alsaedi A, Hayat T (2017) Magnetohydrodynamic flow of Casson fluid over a stretching cylinder. Results Phys 7:498-502

13. Ali F, Sheikh NA, Khan I, Saqib M (2017) Magnetic field effect on blood flow of Casson fluid in axisymmetric cylindrical tube: a fractional model. J Magn Magn Mater 423:327-336

14. Khan MI, Waqas $M$, Hayat $T$, Alsaedi A (2017) A comparative study of Casson fluid with homogeneous-heterogeneous reactions. J Colloid Interface Sci 498:85-90

15. Mabood F, Das K (2019) Outlining the impact of melting on MHD Casson fluid flow past a stretching sheet in a porous medium with radiation. Heliyon 5(2):e01216

16. Pramanik S (2014) Casson fluid flow and heat transfer past an exponentially porous stretching surface in presence of thermal radiation. Ain Shams Eng J 5(1):205-212

17. Choi SU, Eastman JA (1995) Enhancing thermal conductivity of fluids with nanoparticles (No. ANL/MSD/CP-84938; CONF951135-29). Argonne National Lab., IL, USA

18. Basha HT, Sivaraj R, Animasaun IL, Makinde OD (2018) Influence of non-uniform heat source/sink on unsteady chemically reacting nanofluid flow over a cone and plate. In: Kolisnychenko $\mathrm{S}$ (ed) Defect and diffusion forum, vol 389. Trans Tech Publications, Clausthal, pp 50-59

19. Alam MS, Ali M, Alim MA, Munshi MH (2017) Unsteady boundary layer nanofluid flow and heat transfer along a porous stretching surface with magnetic field. In: AIP conference proceedings, vol 1851, no 1. AIP Publishing, p 020023

20. Uddin MJ, Rana P, Bég OA, Ismail AM (2016) Finite element simulation of magnetohydrodynamic convective nanofluid slip flow in porous media with nonlinear radiation. Alex Eng J 55(2):1305-1319

21. Sheikholeslami M, Haq RU, Shafee A, Li Z (2019) Heat transfer behavior of nanoparticle enhanced PCM solidification through an enclosure with V shaped fins. Int J Heat Mass Transf 130:1322-1342

22. Mohyud-Din ST, Khan U, Ahmed N, Rashidi MM (2018) A study of heat and mass transfer on magnetohydrodynamic (MHD) flow of nanoparticles. Propuls Power Res 7(1):72-77

23. Sparrow EM, Eichhorn R, Gregg JL (1959) Combined forced and free convection in a boundary layer flow. Phys Fluids 2(3):319-328

24. Pal D, Mondal H (2010) Effect of variable viscosity on MHD nonDarcy mixed convective heat transfer over a stretching sheet embedded in a porous medium with non-uniform heat source/ sink. Commun Nonlinear Sci Numer Simul 15(6):1553-1564

25. Tavakoli MR, Akbari OA, Mohammadian A, Khodabandeh E, Pourfattah F (2019) Numerical study of mixed convection heat transfer inside a vertical microchannel with two-phase approach. J Therm Anal Calorim 135(2):1119-1134

26. Balootaki AA, Karimipour A, Toghraie D (2018) Nano scale lattice Boltzmann method to simulate the mixed convection heat transfer of air in a lid-driven cavity with an endothermic obstacle inside. Phys A 508:681-701

27. Sakiadis BC (1961) Boundary-layer behavior on continuous solid surfaces: I. Boundary-layer equations for two-dimensional and axisymmetric flow. AIChE J 7(1):26-28

28. Erickson LE, Fan LT, Fox VG (1966) Heat and mass transfer on moving continuous flat plate with suction or injection. Ind Eng Chem Fundam 5(1):19-25

29. Crane LJ (1970) Flow past a stretching plate. ZeitschriftfürangewandteMathematik und Physik ZAMP 21(4):645-647

30. Bachok N, Ishak A, Pop I (2010) Boundary-layer flow of nanofluids over a moving surface in a flowing fluid. Int J Therm Sci 49(9):1663-1668

31. Khan WA, Pop I (2010) Boundary-layer flow of a nanofluid past a stretching sheet. Int J Heat Mass Transf 53(11-12):2477-2483

32. Guo Y, Nguyen TT (2017) Prandtl boundary layer expansions of steady Navier-Stokes flows over a moving plate. Ann PDE $3(1): 10$

33. Ellahi R, Alamri SZ, Basit A, Majeed A (2018) Effects of MHD and slip on heat transfer boundary layer flow over a moving plate based on specific entropy generation. J Taibah Univ Sci 12(4):476-482

34. Pop I, Na TY (1996) Unsteady flow past a stretching sheet. Mech Res Commun 23(4):413-422

35. Young DF, Tsai FY (1973) Flow characteristics in models of arterial stenoses-II. Unsteady flow. J Biomech 6(5):547-559

36. Elbashbeshy EMA, Bazid MAA (2003) Heat transfer over an unsteady stretching surface with internal heat generation. Appl Math Comput 138(2-3):239-245

37. Elbashbeshy EMA, Bazid MAA (2004) Heat transfer over an unsteady stretching surface. Heat Mass Transf 41(1):1-4

38. Ostad-Ali-Askari K, Shayannejad M, Eslamian S, Navabpour B (2018) Comparison of solutions of Saint-Venant equations by characteristics and finite difference methods for unsteady flow analysis in open channel. Int J Hydrol Sci Technol 8(3):229-243 
39. Azam M, Khan M, Alshomrani AS (2017) Effects of magnetic field and partial slip on unsteady axisymmetric flow of Carreau nanofluid over a radially stretching surface. Results Phys 7:2671-2682

40. Sajid M, Ahmad I, Hayat T, Ayub M (2008) Series solution for unsteady axisymmetric flow and heat transfer over a radially stretching sheet. Commun Nonlinear Sci Numer Simul 13(10):2193-2202

41. Shahzad A, Ali R, Hussain M, Kamran M (2017) Unsteady axisymmetric flow and heat transfer over time-dependent radially stretching sheet. Alex Eng J 56(1):35-41

42. Sajid M, Hayat T, Asghar S (2007) Non-similar solution for the axisymmetric flow of a third-grade fluid over a radially stretching sheet. ActaMechanica 189(3-4):193-205

43. Hayat T, Qasim M, Mesloub S (2011) MHD flow and heat transfer over permeable stretching sheet with slip conditions. Int J Numer Meth Fluids 66(8):963-975

44. Hayat T, Khan MI, Alsaedi A, Khan MI (2016) Homogeneousheterogeneous reactions and melting heat transfer effects in the MHD flow by a stretching surface with variable thickness. J Mol Liq 223:960-968

45. Hayat T, Waqas M, Shehzad SA, Alsaedi A (2015) MHD stagnation point flow of Jeffrey fluid by a radially stretching surface with viscous dissipation and Joule heating. J Hydrol Hydromech 63(4):311-317

46. Faraz F, Imran SM, Ali B, Haider S (2019) Thermo-diffusion and multi-slip effect on an axisymmetric Casson flow over a unsteady radially stretching sheet in the presence of chemical reaction. Processes 7(11):851

47. Ahmed J, Begum A, Shahzad A, Ali R (2016) MHD axisymmetric flow of power-law fluid over an unsteady stretching sheet with convective boundary conditions. Results Phys 6:973-981

Publisher's Note Springer Nature remains neutral with regard to jurisdictional claims in published maps and institutional affiliations. 